\title{
WITTGENSTEIN SOBRE LOS MILAGROS COMO IMÁGENES Y PERSPECTIVAS.
}

\section{WITTGENSTEIN ON THE MIRACLES AS \\ IMAGES AND PERSPECTIVES.}

Nicolás Sánchez Durá Universidad de Valencia

\section{Resumen}

El artículo rastrea la filosofía de la religión de Wittgenstein en sus textos más canónicos, centrándose en especial en su concepción o análisis de los milagros. El autor considera que lo que Wittgenstein pensó acerca de los milagros es un lugar oportuno y apropiado para comprender su ética y su limitación de las pretensiones del conocimiento científico.

\begin{abstract}
The article traces the Wittgenstein's philosophy of religion in his canonical texts, focusing especially on his conception or analysis of miracles. The author considers that the Wittgenstein's theory about miracles is an opportune and appropriate place to understand his ethics and his limitation of the claims of totality of science.
\end{abstract}

Palabras clave

Wittgenstein, filosofía de la religión, milagros, cristianismo.

Keywords

Wittgenstein, philosophy of religion, miracles, Christianity. 
La filosofía de la religión de Wittgenstein ha suscitado un notable interés en las dos últimas décadas. Muchos son los artículos y libros aparecidos. Con todo, su concepción o análisis de los milagros sigue siendo un aspecto apenas tematizado. Creo no obstante que lo que Wittgenstein pensó acerca de los milagros es un lugar oportuno y apropiado para aquilatar su ética y su crítica a las pretensiones de totalidad del conocimiento científico. Lo que sigue es solo una primera aproximación ${ }^{1}$ de un trabajo en curso más extenso del que forma parte “'Die künstlerische Betrachtungsweise ...', Wittgenstein on miracles” de próxima aparición.

El punto de vista de Wittgenstein sobre los milagros es coherente con su concepción de la religión. Quizá uno de los lugares donde más claramente sintetiza su punto de vista al respecto sea un fragmento tardío (1947) recogido en Culture and Value donde se refiere no solo al cristianismo, sino a la "fe religiosa" en general:

\begin{abstract}
"Me parece que una fe religiosa podría ser algo así como el apasionado decidirse por un sistema de referencias. Como si además de ser fe, fuera una forma de vida o una forma de juzgar la vida. Una aprehensión apasionada de esta concepción. Y la instrucción en una fe religiosa debería ser, pues, la exposición, la descripción de este sistema de referencias y a la vez un hablar a la conciencia. Y al final ambos deberían tener el efecto de que el instruido mismo, por sí, apresara apasionadamente ese sistema de referencias. Es como si, por una parte, alguien dejara ver mi situación desesperada y, por la otra, pusiera ante mí el instrumento de salvación, hasta que yo, por mí mismo, o en todo caso no llevado de la mano por el instructor, me lanzara sobre ello y lo apresara",
\end{abstract}

Por tan una fe religiosa, un sistema de creencias religioso no es un sistema de proposiciones teóricas o empíricas. Este es un punto en el que Wittgenstein insistió a lo largo de los años 30, donde reflexionó desde una perspectiva comparativa tanto sobre las entonces llamadas “religiones primitivas”, como sobre el carácter del cristianismo en tanto una de las religiones que culturalmente le era más próxima. En este periodo desaparece su énfasis en ver la religión y sus enunciados "como fuera del mundo" (punto de vista propio de le época del Tractatus), pero insiste en no considerar descriptivas sus proposiciones. Los términos de la religión (y de la ética, etc.) forman

\footnotetext{
${ }^{1}$ Este texto se presentó para su discusión en el seno del seminario permanente del Oxford Hume Forum en la sesión del 15 de marzo de 2017 en el Hertford College de la Universiad de Oxford. En la misma sesión participó Vicente Sánfelix con una ponencia sobre Hume y los milagros. De hecho ambas ponecias formaban un díptico.

${ }^{2}$ Wittgenstein, L. Culture and Value \# 375, 1947, Blackwell, Oxford. 1992, p. 64
} 
parte de juegos de lenguaje normativos y expresivos, expresan y evocan actitudes y sentimientos, reflejan compromisos vitales, acompañan o motivan ciertas prácticas y conductas, en definitiva son formas de ver la vida, de tener en perspectiva el mundo y la vida de cada uno. En este sentido, en la década de los 30 (hacia el final) se dedica a criticar, por un lado a quienes conciben la religión como un pensamiento pre-científico (criticando las concepciones evolucionistas de Frazer) y, por otro, a quienes remiten el lenguaje religioso a supuestos hechos que acaecieron en el pasado remoto o que acaecerán tras la muerte. ${ }^{3}$ Dos textos son concluyentes:

"El cristianismo no se basa en una verdad histórica, sino que da una información (histórica) y dice: ¡Ahora cree! Pero no creas esta información con la fe que corresponde a una noticia histórica, sino: cree sin más; y esto solo puede hacerlo como resultado de una vida. Aquí tienes una noticia; no te comportes a su respecto como lo harías con cualquier otra noticia histórica. ¡Deja que tome un lugar completamente distinto en tu vida! ¿En ello no hay paradoja alguna",4

Y también:

"Por extraño que suene: podría probarse que los relatos históricos de los Evangelios son falsos en sentido histórico y con ello la fe no perdería nada; pero no porque se remita quizá a "verdades racionales universales", sino porque la prueba histórica (el juego de pruebas histórico) nada tiene que ver con la fe. Esta noticia (los Evangelios) es aprehendida por la fe (es decir, el amor) de los hombres. Esta es la certeza de este-dar-por-cierto y no otra cosa. Con respecto a estas noticias, el creyente no tiene ni la relación que tiene con una verdad histórica, ni con una teoría de "verdades racionales". Así es. (Hasta con respecto a los distintos tipos de lo que llamamos ficción (Dichtung) se dan posiciones muy diferentes)" 5

Por tanto, las formulaciones religiosas no tienen contenido teorético, no son ni verdades de razón, ni verdades de hecho, en el extremo no son verdades en absoluto y, por ende, no se puede decir de alguna de ellas que sea la verdadera o que otras sean erradas; siempre y cuando el creyente no considere su creencia como una teoría en

\footnotetext{
${ }^{3}$ A este periodo corresponden Las anotaciones sobre 'la Rama Dorada' de Frazer (entre 1931 y 1936), Las lecciones sobre creencia religiosa (editadas por Cyrill Barrett según las notas tomadas por Y. Smithies, R. Rhees y J. Taylor en 1938) y los Movimientos del Pensar (dos periodos de redacción, 193032: 1936-1937); también las anotaciones de Culture and Value de esos años.

${ }^{4}$ Wittgenstein, L. Culture and Value. \# 168, 1937,op.cit., p. 32

${ }^{5}$ Wittgenstein, L. Culture and Value, \# 170, 1937, op.cit., p. 32
} 
absoluto porque entonces ahí radicaría el error. ${ }^{6}$ En el mismo sentido, la certeza de la que gozan las afirmaciones religiosas no es semejante a, o no se pueda analogar con, la certeza empírica, ni tampoco se deduce de un conjunto de axiomas. No se trata aquí de aducir pruebas. Se trata de un “dar por cierto”, es decir de "un apasionado decidirse por un sistema de referencias” que imprime globalmente un determinado sesgo a mi vida y a mi conducta. Veremos que su concepción de los milagros es acorde con esta concepción de la religión.

En la época del Tractatus y de la Conferencia sobre Ética Wittgenstein fija un punto de vista que ya no abandonará: los milagros no son estrictamente hechos. Si presenciamos un hecho inaudito podemos preguntarnos su por qué, podemos buscar sus causas, formular hipótesis...es decir, adoptar un punto de vista científico que puede resultar en una explicación o quedar a la espera de obtener una satisfactoria. Pero adoptando esa actitud científica lo que precisamente ocurre es que despojamos a ese hecho de su carácter milagroso, a menos que por "milagro" entendamos lo que todavía no ha sido explicado por la ciencia. Wittgenstein distingue entre un sentido "relativo” y un sentido “absoluto” de milagro. ${ }^{7}$ Podríamos decir que algo inexplicado, según nuestro conocimiento en un determinado momento de las leyes de la naturaleza, es un milagro en sentido relativo. Pero en sentido absoluto un hecho retiene su carácter de milagro no en función de sus componentes fácticos, sino de una mirada asombrada o admirada que no es la de la ciencia. Así, puesto que lo propiamente milagroso es una forma de consideración admirativa y asombrada, cualquier hecho ordinario puede ser milagroso. Y esa es la razón de que Wittgenstein no dude en describir la "experiencia de asombro ante la existencia del mundo” como "la experiencia de ver el mundo como un milagro.”

\footnotetext{
6 “Sin embargo -podemos objetar- si Agustín no estaba equivocado, lo estaba el santo budista, o cualquier otro, cuya religión expresara concepciones totalmente distintas. Y en cambio ninguno de ellos estaba equivocado, excepto en el momento de formular una teoría". Wittgenstein, L. Observaciones sobre La Rama Dorada de Frazer, Tecnos, Madrid. 1992. p. 50

${ }^{7}$ Wittgenstein, L., [Ante alguien que le creciera un cabeza de león y empezara a rugir y se llamara a un "médico para investigar para investigar científicamente el caso"]: "Esta claro que, en el momento que miráramos las cosas así, todo lo milagrosos habría desaparecido; a menos que entendiéramos por este término simplemente un hecho que todavía no ha sido explicado por la ciencia, cosa que significa que todavía no hemos conseguido agrupar este hecho junto con otros en un sistema científico. Esto muestra que es absurdo decir que la ciencia ha probado que no hay milagros. La verdad es que el modo científico de ver un hecho no es el de verlo como un milagro en el sentido absoluto del término. Pueden ustedes imaginar el hecho que quieran y éste no será en sí milagroso.” Wittgenstein, L., Conferencia sobre ética, Paidós, Barcelona, 1990, p. 41 y 42.
} 
Lo místico no es cómo sea el mundo, sino que el mundo sea, por decirlo en términos del Tractatus (6.44).

Dos anotaciones de una época más tardía (1947) ayudan a comprender lo dicho, lo cual por cierto muestra la continuidad de su pensamiento en este asunto. Wittgenstein habla de los milagros de la naturaleza (Wunder der Nature): "un capullo que se abre y florece”, "un cristal natural”. Y refiere estos dos hechos a dos actitudes posibles: la consideración artística y la del matemático. La mirada de este científico también puede considerar el cristal como "un milagro de la naturaleza" a condición de no transformar su actitud admirativa en una actitud problemática que se interroga por las causas del hecho. Si así fuera, se produce "una desgarradura” que rompe la capacidad de admirase ante el hecho (la cristalización) del cual sabemos incluso de antemano en este caso que se basa en su estructura molecular. ${ }^{8}$ La actitud contraria es la artística: si alguien preguntara “¿pero qué hay de maravilloso en ese florecer?” No cabría más que responder: “¡ve cómo florece!”. Es decir: no cabe aducir razones o argumentar para convencer a alguien de lo que tiene de maravilloso el florecimiento de un capullo. Sé es sensible a ello o no, se deja uno impresionar por ello o no.

Pero una cosa más debe señalarse: al emplear la expresión “milagros de la naturaleza” (Wunder der Nature) Wittgenstein se está distanciando del entendimiento de los milagros como transgresiones de las leyes de naturaleza o como intervenciones sobrenaturales en las relaciones causales del mundo como conjunto de hechos.

A lo largo de los años treinta Wittgenstein volvió sobre los milagros y su enfoque, ahora más desarrollado, es coherente con el punto de vista que acabamos de describir. En efecto, en Los Movimientos del pensar afirma:

\footnotetext{
${ }^{8}$ Wittgenstein, L. "The miracles of nature./One might say: art shows us the miracles of nature. It I based on the concept of the miracles of nature. (Thee blossom, just opening out. What is marvellous (herrlich) about it? We say: "Just look at it opening out!"/....The mathematician too can wonder at the miracles (Wunder) (the crystal) of nature of course; but can he do so once a problem has arisen about what it actually is he contemplating? Is it really possible as long as the object that he finds astonishing and gazes at with awe is shrouded in a philosophical fog? I could imagine somebody might admire not only real trees, but also the shadows or reflections they cast, taking them too for trees. But once he has told himself that these are not really trees after all and he has come to be puzzled at what they are, or at how they are related to trees, his admiration will have suffered a rupture that will need healing” Culture and Value, op.cit. p. 56 y 57
} 
"Si se quieren interpretar los milagros de Cristo, por ejemplo, el milagro de las bodas de Caná, como por ejemplo Dostoievski lo hace, hay que entenderlos como símbolos. La trasformación del agua en vino es, todo lo más, sorprendente y a quien la pudiera llevar a cabo lo miraríamos asombrados, pero nada más. Así pues, eso no puede ser lo maravilloso del caso.- Tampoco lo es que Jesús consiga vino a la gente de la boda y tampoco que les haga llegar el vino de modo tan inaudito. Lo milagroso ha de ser aquello que proporciona contenido y significado a la acción. Y con ello no me refiero a lo extraordinario, o a lo que no ha sucedido nunca, sino al espíritu con el que se hace algo así y del que la trasformación del agua en vino es sólo un símbolo, un gesto (por así decirlo). Un gesto que (efectivamente) sólo puede hacer quien es capaz de hacer eso extraordinario. $\mathrm{Si}$ ha de decirnos algo, hay que entender el milagro como gesto, como expresión. También podría decir: sólo es un milagro cuando lo hace alguien que lo hace con un espíritu milagroso. Sin ese espíritu se trata sólo de un hecho extraordinariamente raro. Es como si hubiera de conocer ya a la persona para poder decir que se trata de un milagro. Tengo que entender la totalidad ya con el espíritu correcto para sentir que ahí se produce un milagro.

Cuando leo en un cuento que una bruja trasforma una persona en un fiera salvaje, es también el espíritu de esa acción el que me produce la impresión."9

Se refiere Wittgenstein en esta anotación a Los Hermanos Karamazov, al cap. IV, “Caná de Galilea”, del libro VII, “Aliosha”: Jesús convirtiendo el agua en vino quiso dar alegría a la gente, pues lo que le importaba no era la pena sino la alegría: “quien quiere a los seres humanos quiere también su alegría”10 (eso es lo que siempre había dicho Sosima ante cuyo féretro está ahora Aliosha, que al oír el relato de las Bodas de Caná leído en voz alta comprende de súbito que ese es su sentido). Pero en el relato de Dostoievski hay algo más que Wittgenstein debió sentir muy cercano: el milagro, i.e. el sentido del relato evangélico del milagro tal como lo refiere Dostoievski, está conectado con un “éxtasis”, con una experiencia de las que Wittgenstein llamaba "mística”: el pasmo o asombro ante la existencia del mundo que Aliosha acaba celebrando al final del capítulo. ${ }^{11}$ Esa experiencia tal como la entiende Wittgenstein es

\footnotetext{
${ }^{9}$ Wittgenstein, L. Movimientos del pensar, (1931). Pre-Textos, Valencia, 2000, pág. 60

${ }^{10}$ Dostoyevski, F. Los Hermanos Karamazov, Alianza Editorial, Madrid, 2011. p. 580

11 "Sobre su cabeza [de Aliosha] se extendía, dilatada y sin fin, la bóveda celeste llena de estrellas de suaves reflejos. Desde el zenit hasta el horizonte parecía doblarse, difusa aún, La Vía Láctea....Las opulentas flores otoñales se habían dormido hasta la mañana en los arriates cercanos a la casa. La paz de la tierra parecía fundirse con el cielo, el misterio terrenal se tocaba con el de las estrellas...Aliosha estaba de pie, mirando, y de repente se dejó caer sobre la tierra como fulminado./ No sabía por qué la abrazaba, no se daba cuenta de la razón por la cual experimentaba un deseo tan irresistible de besarla...pero la besaba llorando...y juró frenéticamente amarla, quererla por los siglos de los siglos....Era como si unos hilos de todos esos infinitos mundos de Dios convergieran de golpe en su alma, y toda ella se le estremecía “al entrar en contacto con los otros mundos.” Sentía deseos de perdonar a todos por todo y
} 
afín a los rasgos que caracterizan lo que W. James en Las variedades de la experiencia religiosa (que Wittgenstein había leído) llamaba “estados de conciencia místicos”: el estado místico se caracteriza por a) no estar articulado lingüísticamente, b) tener una cierta cualidad noética, puesto que no se reduce a un estado de ánimo en el que se produce la unión mística con el todo, sino que arroja cierto tipo de saber, c) es pasivo, algo que a uno le ocurre y d) es transitorio, no duradero.

Todas estas características se dan en la experiencia de Aliosha ante el cadáver del Stárets Zosima. Pero esa experiencia expresable indirectamente a través de la literatura, de las alegorías o de los relatos de los milagros, transforma a Aliosha de una manera muy especial: ve el mundo de otra manera al celebrar su existencia, se reconcilia con él. No es que hayan cambiado los hechos del mundo, sino la manera de verlo, la perspectiva desde la que se considera y valora. O por decirlo a la manera del Tractatus: cambian los límites del mundo y delimitan un espacio ético caracterizado por la reflexión sobre una vida que merezca ser vivida. ${ }^{12}$

En la época del Tractatus lo que nos ofrecían los cuentos de Tolstói, la novela de Dostoievski, los cuentos de brujas, los milagros....-no es tanto una prédica moral explícita cuanto lo que indica el comentario de Wittgenstein sobre el poema El Espino del Conde Eberhard de Uhlam y que Engelmann, en sus recuerdos, resume así: “el poema entero ofrecía en 28 versos la imagen de una vida.” ${ }^{13}$ Esto es: puede decirse que, según la concepción del significado del periodo del Tractatus, lo inexpresable en el lenguaje se ofrece a través de las ficciones literarias como una manera de ver, como una imagen a cuya luz cambia el modo de consideración de la vida. Es decir: como una perspectiva que depende de un cambio de punto de vista y, por tanto, induce una nueva actitud ante la vida.

Pero pongamos ahora el acento no en “imagen”, sino en aquello de lo que la imagen es imagen, es decir en la "vida"-

pedir perdón, oh!, no para sí, no, para todos y por todo; “para mi otros piden”, volvió a resonarle en el alma”. Dostoievski, F. Los Hermanos Karamazov, op.cit, pp. 583

${ }^{12}$ En la Conferencia sobre Ética Wittgenstein conecta tres experiencias personales (el asombro ante que el mundo sea, el sentimiento de completa seguridad pase lo que pase, y el sentimiento de culpa) con una clarificación conceptual sobre qué entiende por Ética más allá de su consideración como "la investigación general sobre lo bueno” (Moore). Para indicar que entiende él por ética, ofrece una lista de expresiones que considera equivalentes: la ética es "la investigación sobre lo valioso o lo que realmente importa...la investigación acerca del significado de la vida o de aquello que hace que la vida merezca vivirse, o de la manera correcta de vivir” Conferencia sobre Ética, op.cit, pp. 34 y 35

13 Engelmann, P., en Wittgenstein-Engelmann, Cartas, Encuentros, Recuerdos. (Edición de Ilse Somavila), Valencia, Pretextos, 2009, p. 136. El subrayado es mío 
Decíamos, según el texto de Movimientos del pensar que se refiere a las bodas de Caná, que lo milagroso no era la rareza del hecho, sino "aquello que proporciona contenido y significado a la acción” de tornar el agua en vino, de tal manera que esa acción se transformaba en un símbolo. Ahora bien, para que se diera esta segunda conversión, es decir para que el hecho se convirtiera en un símbolo, debería encarnar un “espíritu” expresado en el gesto del milagro para cuya comprensión parece que "hubiera de conocer ya a la persona” que lo realiza, es decir, incardinarlo en la personalidad (la totalidad de la vida) de quien lo ejecuta.

Vayamos en primer término con "el gesto". Son multitud los lugares, en este periodo que estamos viendo y posteriormente, donde Wittgenstein dice que la religión no es asunto de palabras, ni de "proposiciones (a lo cual ya me he referido), sino de actitudes, conductas, gestos. De hecho, en la conversación con P. Waissman sobre la ética de Schlick, de 1931, Wittgenstein afirmó:

"puedo imaginar perfectamente una religión en la que no haya doctrinas y, por lo tanto, no utilice el habla. Evidentemente, la esencia de la religión puede no tener nada que ver con el hecho de que se hable (o mejor dicho, si se habla); esto en sí mismo constituye un componente de la conducta religiosa y no una teoría. Por consiguiente, en modo alguno se trata de si las palabras son verdaderas, falsas, o sin-sentidos"14

Y el mismo año de 1931 en Movimientos del pensar repite:

"Se podría imaginar un mundo en el que las personas religiosas se distinguieran de las irreligiosas sólo porque aquellas al caminar dirigieran su mirada hacia arriba mientras que éstas miran al frente. Y aquí el mirar hacia arriba está emparentado de hecho con uno de nuestros gestos religiosos, pero ello no es esencial \& bien podría suceder al contrario que las personas religiosas miraran al frente, etc. Pienso que la religiosidad en este caso no parecería expresada en absoluto por medio de palabras \& que aquellos gestos dirían tanto \& tan poco como las palabras de nuestros escritos religiosos" 15

Ahora bien, como decíamos ese gesto que alguien (Cristo, el santo, etc...) hace se trasforma en un símbolo en virtud del “espíritu” con el que se realiza la acción constituyendo “aquello que proporciona contenido y significado a la acción”. En el

\footnotetext{
${ }^{14}$ Publicada junto a la conferencia sobre ética en The Philosophical Review (1965). Wittgenstein, L. Conferencia sobre Ética, p. 50

${ }^{15}$ Wittgenstein, L., Movimientos del pensar, op.cit, p. 51
} 
pasaje de Los Hermanos Karamazov al que Wittgenstein se refiere, en el velatorio del Stárets Zosima un padre lee el evangelio llegando al episodio de las Bodas de Caná. Al oírlo, Aliosha se dice así mismo:

\begin{abstract}
“Cristo no vino para el dolor, sino para la alegría humana; su primer milagro fue para que unos hombres estuvieran más contentos...”Quien ama la gente ama también la alegría de los hombres...Sin alegría no es posible vivir...Todo cuanto es verdadero y hermoso está siempre repleto de alegría universal." 16
\end{abstract}

Es decir: el gesto cobra sentido en conexión con una perspectiva generalísima sobre cómo debe ser la vida de los hombres, presidida por la alegría y los vínculos fraternos, perspectiva encarnada en la identidad biográfica de Cristo (ficticia o no, pues no habría ningún reparo en considerarlo un personaje literario dado que la fe no se basa en, como ya hemos señalado, en verdades históricas cabiendo incluso, y no por ello se alteraría la fe, la falsedad de los relatos evangélicos).

En Movimientos del pensar, en referencia a la figura de un Apóstol, Wittgenstein de nuevo remite su excepcionalidad a la forma que adopta su vida. Es decir, que lo que otorga sentido simbólico a un gesto es que se incardina en una vida que erigimos en modelo desde el que considerar mi vida y según el cual inspirar mi acción en distintas situaciones y contextos:

"Ser un apóstol es una vida. Esto se manifiesta en parte en lo que dice, pero no que en lo que dice sea verdadero, sino en que él lo diga. Le distingue el sufrir por la idea, pero también vale aquí el sentido de la proposición "este es un apóstol” es su modo de verificación. Describir a un apóstol significa describir una vida. La impresión que esa descripción produzca en otros hay que dejársela a ellos. Creer en un apóstol significa comportarse así \& así con él -comportarse activamente" 17

Ahora bien, los efectos que tengan "la nueva” del apóstol, la impresión que produzca su ejemplo o el espíritu que anima el gesto de Cristo en las bodas de Caná dependen diversamente del estado anímico y la sensibilidad moral de cada uno. Volvemos a encontrar aquí lo que subrayamos al principio: en la fe religiosa se trata de un apasionado compromiso con un sistema de referencias para juzgar y actuar del cual uno se apropia por sí mismo, soberanamente. O dicho de otra manera: el punto de vista

\footnotetext{
${ }^{16}$ Dostoievski, F. Los Hermanos Karamazov, op.cit., p. 580

${ }^{17}$ Wittgenstein, L. Movimientos del Pensar, op.cit., p. 56
} 
religioso, la perspectiva moral que se adopta, no tiene en última instancia un fundamento racional.

Lo cual coincide de nuevo con su punto de vista sobre la ética en general. Una “proposición ética” no es más que una “acción personal”, pero tiene el carácter de "un grito de admiración”. Intentar fundamentar una acción ética no es más que reducirla a otras que "producen alguna impresión. Si al final no tienes aversión por esto o admiración por aquello no hay fundamentación alguna que merezca ese nombre." ${ }^{18} \mathrm{Si}$ se trata de adoptar un sistema de referencias para cambiar mi vida, si hay un primado de la praxis sobre la teoría, entonces la significación de los relatos donde aparece un hecho milagroso ¡o de los cuentos donde una bruja trasforma una persona en un fiera salvaje!, o la impresión que produzca una vida ejemplar hasta el punto que la pueda erigir en modelo, no es independiente de la vida del creyente, de sus aversiones y de sus admiraciones, de su sensibilidad moral previa. Nada puede forzarlo a creer - a adoptar ese sistema de referencias- si el creyente no hace un lugar a ese relato en su vida. En Movimientos del pensar y en referencia a Kierkegaard, afirma:

“Te presento una vida \& ahora tú verás qué actitud tomas al respecto, si te atrae (estimula) vivir así también o qué otro tipo de actitud te provoca. Mediante esa presentación me gustaría, por así decirlo, relajar tu vida.”19

Creo que Wittgenstein mantuvo este punto de vista hasta sus últimos tiempos. En efecto, en una anotación de 1944 de Culture and Value Wittgenstein vuelve sobre la concepción de los milagros que he expuesto pero no en general, sino refiriéndose a sí mismo. Un ejemplo de milagro podría ser que un "santo" hablara y que los árboles que le rodean se inclinaran ante él a modo de reverencia. Pero añade “Ahora bien, creo yo que esto es lo que sucede? No lo creo”, y continua:

"La única forma de creer en un milagro en ese sentido, consistiría en que fuera impresionado por el acontecimiento de esa particular manera. Tanto que tendría que decir, por ejemplo: "Sería imposible ver esos árboles y no sentir que están respondiendo a las palabras”. De modo semejante a como podría decir: "Es imposible ver la cara de este perro y no ver que está alerta y completamente atento a lo que está haciendo su dueño. Me puedo imaginar que la mera narración de las palabras y la vida de un santo pueden

\footnotetext{
${ }^{18}$ Wittgenstein, L. Movimientos del Pensar, op.cit, p. 57

${ }^{19}$ Wittgenstein, L., Movimientos del pensar, op. cit., 1931, pág. 57
} 
hacer que alguien crea la narración de que los árboles se inclinaron. Pero yo no me impresiono así”

De manera que lo que impresiona a unos no impresiona a otros y los “milagros” en cuanto hechos extraños no son prueba de nada, ni tienen significación universal. Por tanto, la capacidad transformadora de los milagros refiere tanto a lo que expresan cuanto al que recibe lo expresado y solo así se aquilata el grado en que algo puede ser “milagroso" para alguien, pues depende de la medida en que le afecta y lo transforma. Si alguien no se maravilla ante un capullo que florece o la presencia de un cristal, no habrá parloteo que le pueda llevar a cambiar su ceguera.

\footnotetext{
${ }^{20}$ Wittgenstein, L., Culture and Value \#498 y 499, 1944
} 